\title{
Problems in measuring the JTC-bias in patients with psychotic disorders with the fish task: a secondary analysis of a baseline assessment of a randomized controlled trial
}

Nico Pytlik ${ }^{1 *}$, Daniel Soll ${ }^{1}$, Klaus Hesse ${ }^{2}$, Steffen Moritz ${ }^{3}$, Andreas Bechdolf ${ }^{4,5}$, Jutta Herrlich ${ }^{6}$, Tilo Kircher ${ }^{1}$, Stefan Klingberg², Martin W. Landsberg', Bernhard W. Müller ${ }^{8}$, Georg Wiedemann $^{9}$, Andreas Wittorf? Wolfgang Wölwer ${ }^{10}$, Michael Wagner ${ }^{6+}$ and Stephanie Mehl ${ }^{1,6 \dagger}$ (D)

\begin{abstract}
Background: The jumping to conclusions bias (JTC) is considered to be an important causal factor in theoretical models for the formation and maintenance of delusions. However, recent meta-analytic findings show a rather equivocal pattern of results regarding associations between JTC and delusions. Thus, the present study aims to investigate in a large sample whether the JTC-bias is more pronounced in patients with psychotic disorders in comparison to controls and whether the JTC bias is associated with a more severe delusional conviction, persecutory delusions, and positive symptoms in general.

Methods: Patients with psychotic disorders $(n=300)$ enrolled in a therapy trial and healthy controls $(n=51)$ conducted a variant of the beads task (fish task) as a measure for the JTC-bias at the start of the trial. Further, clinical interviews were used to assess patients' delusional severity and delusional conviction.
\end{abstract}

Results: There were no statistically significant differences between patients with psychotic disorders (with 53\% displaying the JTC-bias) and controls (41\%). Furthermore, there were no statistically significant correlations between JTC measures and persecutory delusions, delusional conviction, and positive symptoms.

Conclusions: We found no differences in JTC between patients with psychotic disorders and healthy controls, which is in part in line with meta-analytic findings using a wide range of JTC task variants. Interestingly, patients with psychotic disorders displayed JTC rates commonly found in the literature, while healthy control subjects showed an unexpectedly high level of JTC. The task variant we used in the present study (fish task) is discussed as a potential reason for our results, as it may induce a more deliberative reasoning style in controls as compared to the traditional beads task. Furthermore, possible implications for the measurement of the JTC-bias, in general, are discussed.

Trial Registration: ISRCTN29242879 (isrctn.com), date of registration: April 12th 2006, retrospectively registered.

Keywords: Schizophrenia, Psychosis, Delusions, Jumping to conclusions, Cognitive bias, Delusional conviction

\footnotetext{
* Correspondence: nico.pytlik@uni-marburg.de

${ }^{+}$Michael Wagner and Stephanie Mehl shared last authors

'Department of Psychiatry and Psychotherapy \& Center for Mind, Brain and

Behavior (MCMBB), Philipps-University, Rudolf-Bultmann-Str. 8, 35039

Marburg, Germany

Full list of author information is available at the end of the article
}

(c) The Author(s). 2020 Open Access This article is licensed under a Creative Commons Attribution 4.0 International License, which permits use, sharing, adaptation, distribution and reproduction in any medium or format, as long as you give appropriate credit to the original author(s) and the source, provide a link to the Creative Commons licence, and indicate if changes were made. The images or other third party material in this article are included in the article's Creative Commons licence, unless indicated otherwise in a credit line to the material. If material is not included in the article's Creative Commons licence and your intended use is not permitted by statutory regulation or exceeds the permitted use, you will need to obtain permission directly from the copyright holder. To view a copy of this licence, visit http://creativecommons.org/licenses/by/4.0/. The Creative Commons Public Domain Dedication waiver (http://creativecommons.org/publicdomain/zero/1.0/) applies to the data made available in this article, unless otherwise stated in a credit line to the data. 


\section{Background}

Schizophrenia and psychotic disorders are mental disorders that cause severe and often lasting social-cognitive impairments in most patients [1]. A common feature of psychotic disorders are delusions, which are defined as fixed, false beliefs that usually involve disturbances of the interpretation of experiences [2]. Important factors in the formation and maintenance of delusions are various thinking errors or cognitive biases [3, 4]. Probably the most widely studied bias associated with delusions is the jumping to conclusions (JTC) bias [5]. The JTC-bias describes the tendency of individuals to make quick decisions based on what is considered in the literature as little evidence [6].

Traditionally, the JTC-bias is assessed with the beads task [5]. In this task, subjects are presented with two jars containing two types of different colored beads in an opposite ratio (e.g. $85 \%$ black, $15 \%$ white, and vice versa). The jars will be hidden from view before participants are repeatedly presented with single beads from only one jar. Participants are asked after each presentation if they can decide from which jar the beads are drawn. The number of beads subjects require seeing before making a decision is called draws to decision (DTD). Using this experimental setup, healthy subjects usually do not decide after the first or second bead (although the probability for a correct decision after two identical beads already exceeds 94\%), but rather ask for more evidence (additional beads) [7-9]. In contrast, patients with psychotic disorders tend to "jump" to a (most often correct) conclusion about the source (jar) already after bead one or two, and this relatively more "risky" epistemological style is termed JTC-bias.

As misunderstanding is a common problem in terms of the traditional beads task [10], a more easily understandable scenario has been employed in the so-called fish task [11]: in this task variant, instead of beads which are drawn from two jars, a fisherman fishes different colored fish in one of two ponds. The fish task was found to be feasible in detecting a JTC-bias in individuals with higher subclinical paranoia in comparison to individuals with lower subclinical paranoia [12]. Nevertheless, the first studies that compared patients with psychosis and controls in their JTC-bias with the fish task revealed rather equivocal findings with some studies reporting more pronounced JTC-bias in patients with psychosis in comparison to controls [13] and other studies did not find differences in JTC $[14,15]$, possibly due to small sample sizes of the studies that prevented them to detect statistically significant group differences.

In general, the JTC-bias is considered to be a fundamental cognitive factor involved in the formation and maintenance of delusion and other positive symptoms of psychotic disorders [4, 16-18]. This impression especially derives from a plethora of studies that indicate a pronounced tendency of a JTC-bias in patients with psychotic disorders or delusion-prone individuals compared to healthy controls, as summarized in two meta-analyses $[4,8$, 9]. However, most studies relied solely on the data of delusion-prone healthy individuals instead of patients with a diagnosis of a psychotic disorder [9], which complicates the generalization of the results. Moreover, according to meta-analytic findings, the associations between JTC operationalized as a low number of DTD in the beads task and delusion severity are only of small effect size, with metaanalytic significance tests not being significant $[8,9]$. Finally, a recent comparison between meta-analytic evidence and evidence-based on pre-registered studies of the same experimental setup found that meta-analyses systematically overestimate true effects [19].

In the light of the divergent findings, more wellconducted studies with large sample sizes, especially regarding patient samples, are necessary to further clarify the role of the JTC-bias in the formation and maintenance of delusion in patients with psychotic disorders.

One possible explanation for the ambiguous scientific findings is that delusions can be viewed as a multidimensional construct defined by dimensions such as conviction, preoccupation, disruption, and distress [20]. Possibly, the JTC-bias is not generally associated with delusions, but rather with specific dimensions of delusions, e.g. the conviction a person presents regarding a delusion. Indeed, several studies suggest that the JTC-bias is related especially to a more pronounced delusional conviction [2022]. However, given the small number of studies examining the association between the JTC-bias and delusional conviction, these findings should be regarded as preliminary and need further investigation.

Theoretically, the "premature" decision-making [3] in the context of the JTC-bias results in a rapid acceptance of delusional ideas and may consequently contribute to the formation and maintenance of delusional beliefs and positive symptoms in general [4]. However, despite a multitude of studies examining the JTC-bias in psychotic disorders, the topic of different delusional themes (e.g. delusions of persecution) has hardly been researched. This lack of research has been criticized by several authors [12, 23, 24]. Persecutory delusions are the most common delusional theme [25] and most theoretical considerations imply the JTC-bias as an important factor in the formation and maintenance of paranoid ideation and persecutory delusions in particular [23, 26, 27]. Preliminary evidence suggests that interventions targeting reasoning biases like JTC could help to reduce persecutory ideation in patients $[28,29]$. This is why we consider it highly relevant to scrutinize not only the possible association of the JTC-bias and positive symptoms in general but also with the specific symptom domain of persecutory delusions. 
This study aims to assess the JTC-bias and DTD in a large patient sample with the fish task allowing for a detailed analysis of delusional dimensions and delusional content and their association with the JTC-bias. First, in line with prior studies, we hypothesized that patients with psychotic disorders display a more pronounced JTC-bias and lower DTD score compared to healthy controls (hypothesis 1). Second, we predicted less pronounced DTD to be associated with delusional conviction, persecutory delusions in particular and positive symptoms in general (hypothesis 2).

\section{Methods}

\section{Subjects}

The present study is a secondary analysis of the data of 300 patients with schizophrenia-spectrum disorders and 51 healthy controls who participated in the cognitive behavioural therapy for persistent positive symptoms (CBTp) in psychosis trial [30], a multi-centered randomized controlled trial investigating the efficacy of Cognitive Behavior Therapy for Psychosis for patients with psychotic disorders compared to supportive therapy. All six centers were equally involved in recruitment and enrolled an equal number of patients. During the recruitment phase, all patients with psychotic disorders in all inpatient facilities of the participating institutions were informed about the study before discharge and screened for their eligibility. Comparable systematic recruitment strategies were carried out mainly in the outpatient facilities of the centers, but also in assisted living facilities and other support services. All patients with a preliminary diagnosis of a psychotic disorder were recruited, unless they met certain "obvious" exclusion criteria (e.g. lack of language skills or substance dependence as a primary problem). In the case of a refusal to participate in the study, the patient was asked to state the reasons for nonparticipation and to agree with the assessment of symptom severity (PANSS) at this time point. If a patient agreed to participate in the study, more detailed assessments of the inclusion criteria were performed in the course of several appointments, and informed written consent was obtained. All participating patients were randomly assigned to one of the treatment conditions (1:1).

Concerning non-clinical controls, all centers participated equally in their recruitment, which took place via press announcements. Due to the funding restriction, the recruitment plan involved 60 non-clinical controls. Controls were matched with regard to age and gender to the first 60 patients that were enrolled in the study. As the funding was insufficient, recruitment of controls was stopped after enrolling 51 controls.

From the total study sample $(n=330), 9$ patients dropped out before they were asked to participate. Additional 21 patients did not complete the JTC task and were excluded from the sample. The patients included in the analysis $(n=300)$ were diagnosed with schizophrenia $(n=244)$, schizoaffective disorder $(n=37)$, delusional disorder $(n=17)$ and schizophreniform disorder $(n=2)$ using the Structured Clinical Interview for DSM-IV (SKID-IV) [31].

Other inclusion criteria were persistent positive symptoms for at least the last 3 months as indicated by a minimum score of four in item P01 (general delusions; $n=263$ ) and/ or in item P03 (hallucinations: $n=125$; both: $n=88)$ in the Positive and Negative Syndrome Scale (PANSS) [32], age between 18 and 59 years, adequate language fluency and an estimated verbal intelligence quotient (IQ) larger than 70 in the German vocabulary IQ test Mehrfachwahl-Wortschatztest (MWT-B) [33]. One participant with an IQ-score slightly lower than 70 (68) and data of 12 patients without an IQ-score were also included in the analysis, as these patients' verbal fluency was sufficient to participate in the JTC-task and both interventions. Exclusion criteria for controls were mental disorders in their lifetime, excluded with the Structured Clinical Interview for DSM-IV (SCID-IV) [31].

All participants were informed about the assessment and provided written informed consent. This study was approved by the ethics committee at the six centers' medical faculties.

A shortened version of the data set (with the purpose of complete anonymization to meet the strict data protection requirements in Germany) can be obtained from the paper's project page on the OSF (https://osf.io/r3n $5 \mathrm{q} /$ ). In addition, we provide a list of variables that have been used in the analyses, but which will only be made available upon request due to data protection concerns. A more complete data set can be provided by the corresponding author after an individual consultation with our universities' responsible data protection manager.

\section{Measures}

Psychopathology was assessed with the PANSS, which is the most widely used semi-structured clinical interview for assessing symptom severity in patients with schizophrenia [32, 34]. The scale consists of 30 symptoms commonly reported in schizophrenia that can be subsumed to three subscales (positive and negative scale with 7 symptoms each and general psychopathology scale with 16 symptoms). The symptoms are rated on a 7-point Likert scale ranging from 1 (absent) to 7 (extreme). PANSS rating was performed by raters who received ten training sessions in all PANSS items. Interrater reliability (correlation $R^{2}$ ) was satisfactory to high (.92 for the PANSS positive scale and .86 for the PANSS negative scale) [30, 35]. As proposed by Wallwork et al. [36], the PANSS structure is better represented by a 20item, five-factor model with the factors positive factor, 
negative factor, disorganized/ concrete factor, excited factor, and depressed factor. In the present study, the proposed positive factor was used as a measure for positive symptomatology.

The semi-structured Psychotic Symptom Rating Scale (PSYRATS) [37] was used to assess delusional conviction. The scale consists of 7 subscales: amount of preoccupation, duration of preoccupation, disruption of daily life, conviction, amount of distress, and intensity of distress. Interrater reliability and validity were high in a sample of patients with psychotic disorders [37]. In the present study, the subscale delusional conviction was used for further analyses.

The JTC-bias was assessed with a modified version of the beads task [5]. Instead of the classical beads task, in which beads are drawn from different jars, a scenario was used that is easier to understand [11]: the fish task. In this version of the task, a fisherman fishes different colored fish in one out of two ponds. In the fish task, both fish species (blue or orange) were located in the two ponds (A and $\mathrm{B}$ ) in reversed ratio, 80 orange to 20 blue fish in pond $\mathrm{A}$, and 20 orange and 80 blue fish in pond $\mathrm{B}$. The fish are drawn successively from only one of the ponds and the subjects are asked whether they can decide after the first fish is drawn if the fish stems from pond $\mathrm{A}$ or $\mathrm{B}$. This procedure is repeated until ten fish have been presented to them. A decision after one or two fish is considered as JTC-bias. Also, the number of draws to decision (DTD) is recorded: the number of fishes the subjects view until they first decide that the fish stem from one pond. In contrast to the original beads task, in the fish task, subjects are asked to estimate the probability (in percentage) that the fish was selected from pond A or pond B. This measure is called decision threshold. To reduce the difficulty of the task and its demands on working memory, the previously fished and the new fish were constantly displayed in the upper screen area. A research assistant was present throughout the experiment and was available for questions of the participants. The research assistant first explained test instructions and checked whether the participant comprehended them correctly. After each presentation of a fish, the assistant explicitly pointed out to the participant that all fish caught so far should be taken into consideration in the decision-making process. In the case of clear misunderstandings, the assistant informed the participant, that all fish were only caught from one of the ponds. In addition, the fish ratio in both lakes was also displayed continuously, with a colored highlighting of the fish distribution on the screen. The complete study material is available on the project page of the study on the open science framework (https://osf.io/r3n5q/).

The fish task has been previously used to study the specificity of the JTC-bias to delusions [14], the contribution of hypersalience to the JTC-bias [13], and the association of task performance and changes in delusions [11] and yielded significant differences between subjects scoring above- and below average in the Paranoia Checklist $[12,38]$. In the present study, DTD was used as an indicator of JTC, as it is the most reliable JTC measure [7].

\section{Statistical analysis}

Following the central limit theorem [39], variables in samples of $n>30$ can be deemed as normally distributed.

First, patients with psychotic disorders were compared with controls in sociodemographic and clinical variables using Fisher's exact tests and $t$-Tests. In the case of group differences in specific variables, possible relations to the JTC-bias were analyzed and if they were present, variables were included as covariates in subsequent statistical analyses.

The differences between patients with psychotic disorders and controls in JTC (hypothesis 1) were analyzed using Fisher's exact test for the JTC-bias and a $t$-Test for DTD. In the case of heterogeneous variances, we used Welch-Tests to compare patients with controls. In the case of significant results, we used Bonferroni-Holm corrections to control for multiple testing. As effect sizes, we calculated the odds ratio (OR) for dichotomous variables and Hedges' $g$ for continuous variables.

Using Pearson's two-tailed correlations, we examined the relationship between the extent of JTC-bias (DTD) and delusional conviction (PSYRATS delusional conviction), positive symptoms in general (PANSS positive factor), as well as persecutory delusions (PANSS P06; hypothesis 2).

Additional summary statistics and plots can be obtained from the paper's project page on the open science framework (https://osf.io/r3n5q/).

\section{Results}

\section{Sample characteristics}

Table 1 shows the sociodemographic and clinical data of patients with psychotic disorders and non-clinical controls. We did not find any significant statistical differences between the patients and controls in terms of age, gender, or level of education.

However, we found group differences in verbal intelligence scores, assessed with the MWT-B [33] between patients with psychotic disorders and healthy controls, who showed a higher verbal intelligence score. As no significant association between verbal intelligence scores and JTC-measures was found (all $p>.05$ ), no statistical adjustment for verbal intelligence was performed.

\section{Analysis of differences between patients with psychotic disorders and healthy controls (hypothesis 1 )}

As depicted in Table 1, we found no statistically significant differences between patients with psychotic disorders 
Table 1 Means, standard deviations, and comparisons of patients and healthy controls regarding sociodemographic and clinical measures

\begin{tabular}{|c|c|c|c|}
\hline & $\begin{array}{l}\text { Patients with psychotic disorders } \\
(n=300) n(\%) / M(S D)\end{array}$ & $\begin{array}{l}\text { Healthy controls } \\
(n=51) \mathrm{n}(\%) / \mathrm{M}(S D)\end{array}$ & Test Statistics \\
\hline \multicolumn{4}{|l|}{ Sociodemographics } \\
\hline Gender (female) & $117(39 \%)$ & $21(41 \%)$ & $x 2(1)=.097, p=.755$ \\
\hline Age $(y)$ & $37.94(9.68)$ & $35.65(9.30)$ & $t(349)=1.57, p=.117$ \\
\hline Verbal IQ & $106.16(15.08)$ & $114.88(15.37)$ & $t(337)=3.734, p<.001$ \\
\hline Duration of illness (y) & $15.01(9.05)$ & & \\
\hline \multicolumn{4}{|l|}{ PANSS } \\
\hline PANSS total & $64.80(11.38)$ & & \\
\hline PANSS POS & $17.44(3.58)$ & & \\
\hline PANSS NEG & $14.28(4.34)$ & & \\
\hline PANSS GEN & $33.16(7.07)$ & & \\
\hline PANSS positive factor & $11.65(2.72)$ & & \\
\hline PANSS P01 & $4.37(1.11)$ & & \\
\hline PANSS P06 & $3.48(1.48)$ & & \\
\hline \multicolumn{4}{|l|}{ PSYRATS } \\
\hline PSYRATS DS & $2.42(0.76)$ & & \\
\hline PSYRATS AHS & $2.03(1.00)$ & & \\
\hline PSYRATS Delusional conviction & $2.57(1.22)$ & & \\
\hline \multicolumn{4}{|l|}{ JTC measures } \\
\hline JTC-bias present & $160(53 \%)$ & $21(41 \%)$ & $x 2(1)=2.724, p=.099$ \\
\hline Draws to decision (DTD) & $3.10(2.70)$ & $3.49(2.48)$ & $t(349)=.973, p=.331$ \\
\hline Decision threshold & $62.06(29.02)$ & $67.66(28.58)$ & $t(333)=1.26, p=.209$ \\
\hline Subjective probability for Pond A - Draw 1 & $66.60(23.18)$ & $67.18(21.79)$ & $t(349)=.167, p=.868$ \\
\hline Subjective probability for Pond A - Draw 2 & $71.30(19.39)$ & $72.82(17.87)$ & $t(349)=.523, p=.601$ \\
\hline
\end{tabular}

Verbal IQ measured with the MWT-B Mehrfachwahl-Wortschatz-Intelligenztest-B, a German vocabulary IQ test, PANSS positive and negative syndrome scale, POS positive symptoms scale, NEG negative symptoms scale, GEN general psychopathology scale, $P 01$ delusions scale, P06 PANSS persecution/ suspiciousness scale, PSYRATS psychotic symptom rating scale, DS delusions subscale, AHS auditory hallucinations subscale, JTC jumping to conclusions, DTD draws to decision

and controls regarding the presence of the JTC-bias, with Levene's test indicating homogenous variances between the groups $(p=.850)$. On a descriptive level, patients were more likely to display the JTC-bias with an $\mathrm{OR}=1.66$, 95\% CI [.91, 3.02]. Results showed no significant group differences regarding DTD either, with Hedges' $g=0.15$.

\section{Correlations of DTD with different dimensions of delusions (hypothesis 2)}

The results suggest no statistically significant correlation between DTD and PSYRATS delusional conviction $(r=$ $-.097, p=.095)$. Results showed no correlation of DTD and PANSS positive factor [36] or persecutory ideation (PANSS P06) either, with $r=-.096, p=.096$ and $r=$ $-.095, p=.102$ respectively.

The correlations between the other JTC-measures (decision threshold and JTC-bias present) and PSYRATS delusional conviction, PANSS positive factor, and PANS S P06 were likewise all statistically non-significant (all $p>$.05).

\section{Discussion}

Unexpectedly, we did not find evidence for group differences between patients with psychotic disorders and healthy controls with regard to the JTC-bias (draws to decision and the presence of the bias). Moreover, the degree of evidence required before reaching a conclusion (i.e. the number of draws to decision) was neither associated with delusional conviction, positive symptoms in general or persecutory delusions in particular.

\section{Comparison between patients with psychotic disorders and healthy controls in JTC assessed with the fish task} Our results are at odds with meta-analytical findings suggesting a more pronounced JTC and DTD in patients with psychotic disorders when compared to healthy controls [8]. Based on the DTD group differences between patients with psychotic disorders and controls (Hedges $g=0.52)$ reported in the meta-analysis of Dudley et al. [8], the present study had a $96 \%$ power to detect such a 
difference. Thus, the possibility that our results are based on random effects is very unlikely.

The fish task was developed to increase the comprehensibility of the beads task paradigm [11] and has revealed JTC group differences between individuals with lower and higher subclinical paranoia [12]. However, an inspection of the data in Dudley et al. [8] suggests that group differences between patients with psychotic disorders and nonclinical controls are larger for the traditional beads task as compared with the fish task.

It should be taken into account that although patients were preselected based on PANSS P1 delusion item scores/ PANSS P3 hallucination item scores larger than three, in the sample, the mean PANSS total score was quite low $(M=64.80, S D=11.38)$. According to Leucht and colleagues [40], a PANSS total mean score in a patient sample above 57 should be interpreted as "moderately ill", while a total score of 75 indicates that the patient sample can be viewed as "markedly ill". It could be argued that the relatively moderate mean score of symptom severity in the patient sample could explain the non-significant group differences, as differences between the patient sample and controls might have been reduced. However, this interpretation seems unlikely, as the proportion of patients who presented the JTC-bias in our study with the fish task is comparable with other studies using the beads task (about 50\%) [20, 41, 42], while the proportion of controls in our study who presented the JTC-bias (41\%) is about three to four times higher compared to other studies with the beads task [10, 23, 43]. However, other studies with the fish task also found that their control sample showed a less cautious behavior with $44 \%$ [15] and $42 \%$ [14] of the control sample displaying a JTC bias, and these studies also found no significant JTC differences between psychotic patients and controls. Given these results, it seems more likely that the fish task, while formally similar to the beads task, may induce a generally less cautious decision behavior, particularly in controls.

Thus, while our test power was ideal, our control sample seems to present a pronounced tendency to present a JTC-bias, and consequently, we were unable to detect group differences in JTC, in line with the two other studies that comparably used the fish task. Concluding, it is important to take a close look at the task characteristics in the fish task, in contrast to the traditional beads task.

\section{Methodological considerations on the fish task}

How can we explain the different findings concerning group differences between patients with psychotic disorders and controls in the beads task vs. the fish task?

One explanation of differences between the beads task and the fish task might be that we used a task variant of the fish task designed to simultaneously measure DTD and the decision threshold of the subjects. In this variant, participants are first asked to decide from which original pond the fish they see on the screen were fished. Next, they are additionally asked to estimate the respective probability for the fish to stem from one of the two ponds (this procedure is then repeated ten times). It is possible that the healthy control sample we assessed in the study might have been triggered by the additional probability estimation task to show a "riskier" response behavior [12]. This explanation is supported by the results of the two other studies that used the same variant of the fish task and compared the JTC-bias between patients with psychotic disorders and healthy controls who also did not find statistically significant group differences between both groups $[14,15]$.

A second explanation of the conflicting results is based on different experimental procedures. On the one hand, in the classical beads task, participants are asked after each presentation of a bead, if they can decide from which jar the beads are drawn. If the participants decide for a jar, the trial is completed. On the other hand, in the fish task, if participants decide that the fish stem from one pond, the trial is continued until ten fish are drawn. Thus, the traditional beads task might result in a more cautious decision-making behavior in healthy subjects, as the decision is definite and subjects are asked only to decide once they are "completely sure" [44] and this might explain the more cautious behavior other groups and we detected in the control group.

\section{Lack of associations with psychopathology}

While the task format may have been responsible for a riskier decision behavior, subjects still differ regarding the evidence required before they reach a decision. We also set out to investigate whether DTD relates to delusional conviction as well as positive symptomatology in general and persecutory delusions in particular. Surprisingly, we did not find a correlation between DTD and delusional conviction in the patient sample. This is not in line with past research, as several studies that used the beads task suggest that a low DTD score is related especially to a more pronounced delusional conviction in patients with psychotic disorders $[20,21]$ and delusion-prone individuals [20-22]. Nevertheless, our results are in line with the two recent meta-analyses that did not find significant associations between DTD and delusion severity in currently deluded patients with psychotic disorders and delusion-prone individuals $[8,9]$, also their results are primarily or solely based on studies with the beads task.

Interestingly, studies that used the fish task also did not find significant correlations between DTD and measures of delusion severity in controls [12] and patients with psychotic disorders [14]. Thus, as discussed above, it is important to pay close attention to our task variant, the fish task, to explain the different results. 
With regard to associations between the JTC-bias and delusions, results point generally more in the direction that associations are less pronounced than previously assumed and that the importance of the JTC-bias for delusion severity has been overestimated to some degree in the past in theoretical models. Although the present study is not a direct replication of previous studies regarding the measurement of the JTC-bias, it is important to take our results into careful account, especially in light of a large scale study that also found that delusional ideation did not predict DTD (measured with the beads task) [45]. Additionally, meta-analytical results primarily obtained with the beads task $[8,9]$ based on a large number of studies also point in the same direction.

Interestingly, in the fish task variant other groups and we used, participants first view one (and then two) orange fish and are repeatedly asked whether they can decide if the fish stem from the orange pond. Mathematical analysis reveals probabilities for a correct decision of $80 \%$ after the first draw and 94,1\% after the second draw for the fish task (using a ratio of $80: 20$ ), providing the participants with Bayesian factors of four (first draw) respectively 32 (second draw). Bayesian factors of this size are considered "positive" respectively "strong" evidence in the context of data analysis in research [46, 47], deciding at that stage rather rational than biased.

Since not all decisions after one or two fish should be nominated as "jumping to conclusions", we stress the importance of an analysis of the probabilities. This could explain the rather "equivocal" findings on associations between JTC and delusions (review of Garety and Freeman [4]) that might depend on the probabilities of a correct decision based on the specific fish/bead sequence and ratio framing the JTC-bias (decision after 1-2 fish/ beads) as rather more or less risky/rational.

Furthermore, as misunderstandings of the instructions of the beads task occur more often in patients with psychosis than in healthy controls [10], they could also contribute and enlarge the frequently found group differences between patients and healthy controls. This interpretation is supported by the findings of a large study by Tripoli et al. [48], which found that the association between JTC and psychotic symptoms in patients with psychosis seems to be mediated to a large extent by the IQ of the subjects. Therefore, JTC may be a consequence of more basal cognitive deficits, which may contribute to a misunderstanding of the task. If the fish task is indeed easier to understand in comparison to other task variants, this could be accompanied by a more "rational" response behavior on the part of the patients, which is more in line with the response behavior of nonclinical control subjects. Consequently, the fish task could be a valid measurement method for the JTC bias, which, however, occurs much less frequently in patients with psychosis, if their correct understanding of the task is ensured, as compared to studies using the traditional beads task paradigm that is harder to correctly understand.

It is possible that the decision behavior we measure in the beads task/fish task (whether it is risky or rational) might be still an interesting causal factor involved in the formation and maintenance of symptoms of psychotic disorders. Nevertheless, it might not be causally related to delusions in particular, but rather associated with other symptoms of psychotic disorders such as negative symptoms $[49,50]$, insight [51] or neurocognitive problems [52] (Interestingly, in an exploratory analysis, we found negative symptoms to be associated with JTC, $r=$ $-.166, p<.05)$.

This is reminiscent of another cognitive bias, a deficit in theory of mind, that first seemed like a vital factor in the formation of delusions but later proved to be rather associated with negative and disorganization symptoms [4]. Moreover, as more and more studies raise doubts about the importance of the JTC-bias for delusions, future studies could also focus on other possible factors in the formation and maintenance of delusions, like emotional processes such as worrying, low self-esteem, or negative affect [4].

In future studies that aim to analyze group differences between patients with psychotic disorders and controls, first, it is important to use a more reliable assessment of JTC, possibly by combining different fish ratios (80:20, 60:40) and different sequences of fish/beads (see Speechley et al. [13] for an analysis of probability estimations for different fish sequences and ratios) and pay close attention to the probability for a correct decision after one or two fish in the task that is used, as it could vary largely and result in either a statistically more premature or a more risky decision. Interestingly, neither the traditional beads task nor the fish task paradigm provides a definite correct decision regarding the required number of beads. It would be interesting to address the question of the optimal decision threshold further in future research, possibly by providing incentives for more cautious decisions and by analyzing ROC-curves of decisions. Future research could also build on variants of the fish task that incentivize optimal levels of data gathering [53], which in turn would allow a clear identification of "premature" decisions. Also, the measurement of the JTC-bias could be performed with different task materials (e.g., emotional salient material) [54], additional measures (e.g. the Cognitive Biases Questionnaire for Psychosis) [55] or new task variants (e.g. the box-task [56] and the "what is this" task [44, 57]).

Furthermore, future studies are well-advised to preregister their hypotheses and analyses, as studies that are not preregistered tend to overestimate effects [19]. Finally, in future meta-analyses on JTC, it would also be 
interesting to take the probability of a correct decision after one or two fish into account, as it might not always be an "extreme" decision [8], but in the case of the fish task, often a rational decision.

\section{Strength and limitations}

The present study has some notable features. We set out to investigate the JTC-bias in a large, patient sample to fill a gap that became apparent in the meta-analyses mentioned above [8]. Due to the large sample size, the broad variance in positive symptoms, and the measurement of delusions using two interviews, the nonsignificance of our results should encourage a discussion of the measurement of the JTC-bias in general, which goes beyond the mere criticism of the fish task.

However, the study has some important limitations. First, only hypothesis 2 (association of JTC with delusional symptoms) was preregistered in the trial proposal. The control group was only included in the study design during the study and group comparisons between healthy control subjects and patients were not the main objective of the study, which primarily aimed to compare the effectiveness of CBTp and supportive therapy in treating patients with psychotic symptoms and to analyze putative mediators (e.g. cognitive biases such as the JTC-bias) of change in CBTp. Thus, our results regarding group differences between patients with psychosis and controls are exploratory and should be investigated again in a preregistered design. Furthermore, only a limited budget was available for the assessment of a nonclinical control group, which is why a further criticism of the study might relate to the unequal group size regarding the patient sample and the healthy control subjects. Although unbalanced group sizes may be associated with statistical problems, we would have achieved a power of approximately beta $=.99$ for absolute differences in JTC rates (based on a JTC rate of $50 \%$ in patients and $20 \%$ in healthy controls $[10,20,23,41,42])$, and .96 for group differences in DTD at the effect sizes reported in the literature [8]. As none of the assumptions for the statistical tests carried out are violated, the results can be considered relatively robust despite the different group sizes [58]. Nevertheless, we have re-examined the results using the non-parametric Mann-Whitney-U test, which also does not show significant group differences in DTD. Furthermore, as discussed before, the task variant with the simultaneous measurement of the decision threshold might be responsible for the non-significance of our results. Additionally, as we did not measure the delusion severity of the healthy subjects, we cannot rule out the possibility that our healthy control sample consisted of delusion-prone individuals who might also display a higher level of JTCbias, in line with other studies in delusion-prone subjects $[59,60]$. While we excluded controls who had a mental disorder in their past/ present, we did not assess delusional ideation in the control group (e.g. with questionnaires like the Peters et al. Delusions Inventory) [61]. Thus, our control sample might be more prone to delusional ideation and consequently, we did not find group differences in JTC.

\section{Conclusions}

We did not find evidence for group differences between patients with psychotic disorders and healthy controls regarding the JTC-bias, as measured by the fish task. Furthermore, the JTC-bias was not associated with delusional conviction, positive symptoms in general or persecutory delusions in particular. Overall, associations between the JTC-bias and delusional conviction and positive symptoms might be smaller than previously assumed. The authors, among whom is one of the developers of the fish task variant used in this trial, conclude by arguing that there is an urgent need to rethink the fish task and perhaps also the traditional beads task paradigm as the standard measure for JTC, especially if it includes the simultaneous measurement of the decision threshold of the subjects. Further, it is important to take into account the probability of a correct decision in the task, as it is not always premature.

\section{Abbreviations \\ CBTp: cognitive behavioural therapy for persistent positive symptoms; DTD: draws to decision; JTC: jumping to conclusions; MWT-B: Mehrfachwahl- Wortschatztest; OR: Odds Ratio; PANSS: Positive and Negative Syndrome Scale; PSYRATS: Psychotic Symptom Rating Scale}

\section{Acknowledgments}

Gudrun Sartory, one of the initiators and principal investigators of the present study, sadly passed away in 2015. We owe much to her leadership, optimism, and lasting support. We would like to thank Jürgen Brinkmeyer for programming the ER task. We would like to thank all participants in the study and all members of the POSITIVE study: S. Baal, J. Berning, S. Beulen, G. Buchkremer, A. Büch, B. Conradt, Y. Eikenbusch, W. Gaebel, A. Gawronski, J. Güttgermans, A. Herold, U. Jakobi-Malterre, I. Lengsfeld, W. Maier, K. Platt, B. Pohlmann, A. Rotarska-Jagiela, S. Sickinger, H. Smoltczyk, S. Unsöld, A. Vogeley, A. Witt, L. Zipp.

\section{Authors' contributions}

$\mathrm{AB}, \mathrm{KH}, \mathrm{JH}, \mathrm{TK}, \mathrm{SK}, \mathrm{ML}, \mathrm{BM}, \mathrm{SMO}, \mathrm{GW}, \mathrm{AW}, \mathrm{WW}$, and MW designed the study and wrote the protocol and the trial proposal, NP and SMe performed the statistical analysis, NP and SMe managed the literature search and wrote the first draft of the manuscript, DS, SMe and MW co-wrote the manuscript. All authors contributed to and have approved the final manuscript.

\section{Funding}

This work was supported by grants awarded by the German Federal Ministry of Education and Research (BMBF: 01GV0618, 01GV0620). The study was part of the BMBF research program "Research Networks on Psychotherapy." The German Federal Ministry of Education and Research was neither involved in the design of the study, the data collection, the data analysis, the interpretation of data nor in writing the manuscript. Open Access funding enabled and organized by Projekt DEAL.

Availability of data and materials

Study materials, additional summary statistics and plots, and a shortened version of the data set (with the purpose of complete anonymization to meet the strict data protection requirements in Germany) can be obtained 
from the paper's project page on the OSF (https://osf.io/r3n5q/). A more complete data set can be provided by the corresponding author after an individual consultation with our universities' responsible data protection manager.

\section{Ethics approval and consent to participate}

All participants were informed about the assessment and gave written informed consent. In case of a legal guardian, the patients and the guardian were informed about the assessment and both the patient and the guardian gave written informed consent. The ethics committees at the six centers' medical faculties (University of Bonn, Cologne, Duesseldorf, Frankfurt, Tuebingen, and Duisburg-Essen) approved the study.

\section{Consent for publication}

Not applicable.

\section{Competing interests}

SMe, AB, KH, SK, TK, AW, SMo and WW have published manuals/ chapters of textbooks and presented workshops and supervision in CBT (all) or Metacognitive Training / Therapy for psychosis (SMo). All authors declare that they have no competing interests.

\section{Author details}

'Department of Psychiatry and Psychotherapy \& Center for Mind, Brain and Behavior (MCMBB), Philipps-University, Rudolf-Bultmann-Str. 8, 35039 Marburg, Germany. ${ }^{2}$ Department of Psychiatry and Psychotherapy, University of Tübingen, Tübingen, Germany. ${ }^{3}$ Department of Psychiatry and Psychotherapy, University of Hamburg, Hamburg, Germany. ${ }^{4}$ Department of Psychiatry and Psychotherapy, University of Cologne, Cologne, Germany. ${ }^{5}$ Department of Psychiatry and Psychotherapy, Vivantes Klinikum am Urban Teaching Hospital Charité Universitätsmedizin Berlin, Berlin, Germany. ${ }^{6}$ Department of Psychiatry, Psychosomatics and Psychotherapy, University of Frankfurt, Frankfurt, Germany. ${ }^{7}$ Department of Psychiatry and Psychotherapy, Friedrich-Wilhelms University of Bonn, Bonn, Germany. ${ }^{8}$ Department of Psychiatry and Psychotherapy, University of Duisburg-Essen, Essen, Germany. ${ }^{9}$ Departmenf of Psychiatry and Psychotherapy, Hospital Fulda, Fulda, Germany. ${ }^{10}$ Department of Psychiatry and Psychotherapy, Medical Faculty, Heinrich-Heine University of Düsseldorf, Düsseldorf, Germany.

Received: 17 March 2020 Accepted: 16 November 2020 Published online: 23 November 2020

\section{References}

1. Fett A-KJ, Viechtbauer W, Dominguez M-d-G, Penn DL, van Os J, Krabbendam $L$. The relationship between neurocognition and social cognition with functional outcomes in schizophrenia: a meta-analysis. Neurosci Biobehav Rev 2011;35:573-588. doi:https://doi.org/10.1016/j. neubiorev.2010.07.001.

2. American Psychiatric Association. Diagnostic and statistical manual of mental disorders: DSM-5. 5th ed. Washington, DC: American Psychiatric Publ; 2013.

3. Moritz S, Scheu F, Andreou C, Pfueller U, Weisbrod M, Roesch-Ely D. Reasoning in psychosis: risky but not necessarily hasty. Cogn Neuropsychiatry. 2016;21:91106. https://doi.org/10.1080/13546805.2015.1136611.

4. Garety PA, Freeman D. The past and future of delusions research: from the inexplicable to the treatable. Br J Psychiatry. 2013;203:327-33. https://doi. org/10.1192/bjp.bp.113.126953.

5. Huq SF, Garety PA, Hemsley DR. Probabilistic Judgements in deluded and non-deluded subjects. Q J Exp Psychol Section A. 1988;40:801-12. https:// doi.org/10.1080/14640748808402300.

6. Moritz S, Woodward TS. Jumping to conclusions in delusional and nondelusional schizophrenic patients. Br J Clin Psychol. 2005;44:193-207. https://doi.org/10.1348/014466505X35678.

7. Fine C, Gardner M, Craigie J, Gold I. Hopping, skipping or jumping to conclusions? Clarifying the role of the JTC bias in delusions. Cogn Neuropsychiatry. 2007;12:46-77. https://doi.org/10.1080/ 13546800600750597.

8. Dudley R, Taylor P, Wickham S, Hutton P. Psychosis, delusions and the "jumping to conclusions" reasoning Bias: a systematic review and meta-analysis. Schizophr Bull. 2016;42:652-65. https://doi.org/10.1093/ schbul/sbv150.
9. Ross RM, McKay R, Coltheart M, Langdon R. Jumping to conclusions about the beads task? A meta-analysis of delusional ideation and data-gathering Schizophr Bull. 2015;41:1183-91. https://doi.org/10.1093/schbul/sbu187.

10. Balzan R, Delfabbro PH, Galletly CA, Woodward TS. Over-adjustment or miscomprehension? A re-examination of the jumping to conclusions bias. Aust N Z J Psychiatry. 2012;46:532-40. https://doi.org/10.1177/ 0004867411435291

11. Woodward TS, Munz M, LeClerc C, Lecomte T. Change in delusions is associated with change in "jumping to conclusions". Psychiatry Res. 2009; 170:124-7. https://doi.org/10.1016/j.psychres.2008.10.020.

12. Moritz S, van Quaquebeke N, Lincoln TM. Jumping to conclusions is associated with paranoia but not general suspiciousness: a comparison of two versions of the probabilistic reasoning paradigm. Schizophr Res Treatment. 2012;2012:384039. https://doi.org/10.1155/2012/384039.

13. Speechley W, Whitman J, Woodward TS. The contribution of hypersalience to the "jumping to conclusions" bias associated with delusions in schizophrenia. J Psychiatry Neurosci. 2010;35:7-17. https://doi.org/10.1503/jpn.090025.

14. Wittorf A, Giel KE, Hautzinger M, Rapp A, Schönenberg M, Wolkenstein L, et al. Specificity of jumping to conclusions and attributional biases: a comparison between patients with schizophrenia, depression, and anorexia nervosa. Cogn Neuropsychiatry. 2012;17:262-86. https://doi.org/10.1080/ 13546805.2011.633749

15. Andreou C, Roesch-Ely D, Veckenstedt R, Bohn F, Aghotor J, Köther U, et al. Predictors of early stable symptomatic remission after an exacerbation of schizophrenia: the significance of symptoms, neuropsychological performance and cognitive biases. Psychiatry Res. 2013;210:729-34. https:// doi.org/10.1016/j.psychres.2013.08.019.

16. Ward T, Garety PA. Fast and slow thinking in distressing delusions: a review of the literature and implications for targeted therapy. Schizophr Res. 2017. https://doi.org/10.1016/j.schres.2017.08.045.

17. Preti A, Cella M. Paranoid thinking as a heuristic. Early Interv Psychiatry. 2010;4:263-6. https://doi.org/10.1111/j.1751-7893.2010.00190.x.

18. Bentall RP, de Sousa P, Varese F, Wickham S, Sitko K, Haarmans M, Read J. From adversity to psychosis: pathways and mechanisms from specific adversities to specific symptoms. Soc Psychiatry Psychiatr Epidemiol. 2014; 49:1011-22. https://doi.org/10.1007/s00127-014-0914-0.

19. Kvarven A, Strømland E, Johannesson M. Comparing Meta-Analyses and PreRegistered Multiple Labs Replication Projects; 2019.

20. Garety PA, Freeman D, Jolley S, Dunn G, Bebbington PE, Fowler DR, et al. Reasoning, emotions, and delusional conviction in psychosis. J Abnorm Psychol. 2005;114:373-84. https://doi.org/10.1037/0021-843X.114.3.373.

21. Gawęda $Ł$, Prochwicz K. A comparison of cognitive biases between schizophrenia patients with delusions and healthy individuals with delusionlike experiences. Eur Psychiatry. 2015;30:943-9. https://doi.org/10.1016/j. eurpsy.2015.08.003.

22. McKay R, Langdon R, Coltheart M. Need for closure, jumping to conclusions, and decisiveness in delusion-prone individuals. J Nerv Ment Dis. 2006;194: 422-6. https://doi.org/10.1097/01.nmd.0000221353.44132.25.

23. Freeman D. Suspicious minds: the psychology of persecutory delusions. Clin Psychol Rev. 2007:27:425-57.

24. Gawęda $Ł$, Staszkiewicz M, Balzan RP. The relationship between cognitive biases and psychological dimensions of delusions: the importance of jumping to conclusions. J Behav Ther Exp Psychiatry. 2017;56:51-6. https://doi.org/10.1016/j.jbtep.2016.08.003.

25. Brakoulias $\vee$, Starcevic $V$. A cross-sectional survey of the frequency and characteristics of delusions in acute psychiatric wards. Australas Psychiatry. 2008;16:87-91. https://doi.org/10.1080/10398560701633176.

26. Bentall RP, Corcoran R, Howard R, Blackwood N, Kinderman P. Persecutory delusions: a review and theoretical integration. Clin Psychol Rev. 2001;21:1143-92.

27. Bentall RP, Rowse G, Shryane N, Kinderman P, Howard R, Blackwood N, et al. The cognitive and affective structure of paranoid delusions: a transdiagnostic investigation of patients with schizophrenia spectrum disorders and depression. Arch Gen Psychiatry. 2009;66:236-47. https://doi. org/10.1001/archgenpsychiatry.2009.1.

28. Freeman D, Garety PA. Advances in understanding and treating persecutory delusions: a review. Soc Psychiatry Psychiatr Epidemiol. 2014;49:1179-89. https://doi.org/10.1007/s00127-014-0928-7.

29. Garety PA, Waller H, Emsley R, Jolley S, Kuipers E, Bebbington P, et al. Cognitive mechanisms of change in delusions: an experimental investigation targeting reasoning to effect change in paranoia. Schizophr Bull. 2015;41:400-10. https://doi.org/10.1093/schbul/sbu103. 
30. Klingberg S, Wittorf A, Meisner C, Wölwer W, Wiedemann G, Herrlich J, et al. Cognitive behavioural therapy versus supportive therapy for persistent positive symptoms in psychotic disorders: the POSITIVE study, a multicenter, prospective, single-blind, randomised controlled clinical trial. Trials. 2010;11: 123. https://doi.org/10.1186/1745-6215-11-123.

31. Wittchen H-U, Wunderlich U, Gruschwitz S, Zaudig M. SKID: Strukturiertes Klinisches Interview für DSM-IV. Achse 1 und 2 [SCID: Structured Clinical Interview for DSM-IV. Axis I and II]. Göttingen: Hogrefe; 1997.

32. Kay SR, Fiszbein A, Opler LA. The positive and negative syndrome scale (PANSS) for schizophrenia. Schizophr Bull. 1987:13:261-76.

33. Lehrl S. Manual zum MWT-B: [Mehrfachwahl-Wortschatz-Intelligenztest]. 5th ed. Balingen: Spitta-Verl; 2005.

34. Warman DM, Martin JM, Lysaker P. Jumping to conclusions and delusions: the impact of discussion of the bias on the bias. Schizophr Res. 2013;150: 575-9. https://doi.org/10.1016/j.schres.2013.09.003.

35. Mehl S, Landsberg MW, Schmidt A-C, Cabanis M, Bechdolf A, Herrlich J, et al. Why do bad things happen to me? Attributional style, depressed mood, and persecutory delusions in patients with schizophrenia. Schizophr Bull. 2014;40:1338-46. https://doi.org/10.1093/schbul/sbu040.

36. Wallwork RS, Fortgang R, Hashimoto R, Weinberger DR, Dickinson D. Searching for a consensus five-factor model of the positive and negative syndrome scale for schizophrenia. Schizophr Res. 2012;137: 246-50. https://doi.org/10.1016/j.schres.2012.01.031.

37. Haddock G, McCarron J, Tarrier N, Faragher EB. Scales to measure dimensions of hallucinations and delusions: the psychotic symptom rating scales (PSYRATS). Psychol Med. 1999;29:879-89.

38. Freeman D, Garety PA, Bebbington PE, Smith B, Rollinson R, Fowler DR, et al. Psychological investigation of the structure of paranoia in a nonclinical population. Br J Psychiatry. 2005;186:427-35. https://doi.org/10.1192/ bjp.186.5.427.

39. Weinberg SL, Abramowitz SK. Statistics using SPSS: an integrative approach. 2nd ed. Cambridge: Cambridge University Press; 2008.

40. Leucht S, Kane JM, Kissling W, Hamann J, Etschel E, Engel RR. What does the PANSS mean? Schizophr Res. 2005;79:231-8. https://doi.org/10.1016/j.schres. 2005.04.008.

41. Menon M, Pomarol-Clotet E, McKenna PJ, McCarthy RA. Probabilistic reasoning in schizophrenia: a comparison of the performance of deluded and nondeluded schizophrenic patients and exploration of possible cognitive underpinnings. Cogn Neuropsychiatry. 2006;11:521-36. https://doi. org/10.1080/13546800544000046.

42. Dudley R, Shaftoe D, Cavanagh K, Spencer H, Ormrod J, Turkington D, Freeston M. 'Jumping to conclusions' in first-episode psychosis. Early Interv Psychiatry. 2011;5:50-6. https://doi.org/10.1111/j.1751-7893.2010.00258.x.

43. Cafferkey K, Murphy J, Shevlin M. Jumping to conclusions: the association between delusional ideation and reasoning biases in a healthy student population. Psychosis. 2013;6:206-14. https://doi.org/10. 1080/17522439.2013.850734

44. Moritz S, Göritz AS, Balzan RP, Gawęda Ł, Kulagin SC, Andreou C. A new paradigm to measure probabilistic reasoning and a possible answer to the question why psychosis-prone individuals jump to conclusions. J Abnorm Psychol. 2017:126:406-15. https://doi.org/10.1037/abn0000262.

45. Ross RM, Pennycook G, McKay R, Gervais WM, Langdon R, Coltheart M. Analytic cognitive style, not delusional ideation, predicts data gathering in a large beads task study. Cogn Neuropsychiatry. 2016;21:300-14. https://doi. org/10.1080/13546805.2016.1192025.

46. Körber M. Einführung in die inferenzstatistische Auswertung mit BayesStatistik. Ergonomie aktuell. 2016;017:20-6.

47. Jarosz AF, Wiley J. What are the odds?: a practical guide to computing and reporting Bayes factors. J Probl Solving. 2014. https://doi.org/10.7771/19326246.1167.

48. Tripoli G, Quattrone D, Ferraro L, Gayer-Anderson C, Rodriguez V, La Cascia $C$, et al. Jumping to conclusions, general intelligence, and psychosis liability: findings from the multi-centre EU-GEl case-control study. Psychol Med. 2020:1-11. https://doi.org/10.1017/S003329171900357X

49. Bentham AM, McKay AP, Quemada I, Clare L, Eastwood N, McKenna PJ. Delusions in schizophrenia: a phenomenological and psychological exploration. Cogn Neuropsychiatry. 1996;1:289-304. https://doi.org/10.1080/ 135468096396451.

50. Lincoln TM, Ziegler M, Mehl S, Rief W. The jumping to conclusions bias in delusions: specificity and changeability. J Abnorm Psychol. 2010;119:40-9. https://doi.org/10.1037/a0018118.
51. Reese HE, McNally RJ, Wilhelm S. Probabilistic reasoning in patients with body dysmorphic disorder. J Behav Ther Exp Psychiatry. 2011;42:270-6. https://doi.org/10.1016/j.jbtep.2010.11.005.

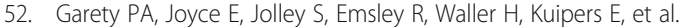
Neuropsychological functioning and jumping to conclusions in delusions. Schizophr Res. 2013;150:570-4. https://doi.org/10.1016/j.schres.2013.08.035.

53. van der Leer L, Hartig B, Goldmanis M, McKay R. Delusion proneness and 'jumping to conclusions': relative and absolute effects. Psychol Med. 2015; 45:1253-62. https://doi.org/10.1017/S0033291714002359.

54. Dudley $\mathrm{R}$, John $\mathrm{CH}$, Young AW, Over DE. The effect of self-referent material on the reasoning of people with delusions. Br J Clin Psychol. 1997;36(Pt 4): 575-84.

55. Peters ER, Moritz S, Schwannauer M, Wiseman Z, Greenwood KE, Scott J et al. Cognitive biases questionnaire for psychosis. Schizophr Bull. 2014;40: 300-13. https://doi.org/10.1093/schbul/sbs199.

56. Andreou C, Schneider BC, Braun V, Kolbeck K, Gallinat J, Moritz S. Dopamine effects on evidence gathering and integration. J Psychiatry Neurosci. 2015; 40:422-8. https://doi.org/10.1503/jpn.140306.

57. Serrano-Guerrero E, Ruiz-Veguilla M, Martín-Rodríguez A, RodríguezTestal JF. Inflexibility of beliefs and jumping to conclusions in active schizophrenia. Psychiatry Res. 2020;284:112776. https://doi.org/10.1016/j. psychres.2020.112776.

58. Glass GV, Peckham PD, Sanders JR. Consequences of failure to meet assumptions underlying the fixed effects analyses of variance and covariance. Rev Educ Res. 1972;42:237-88. https://doi.org/10.3102/ 00346543042003237

59. van Dael F, Versmissen D, Janssen I, Myin-Germeys I, van Os J, Krabbendam L. Data gathering: biased in psychosis? Schizophr Bull. 2006;32:341-51. https://doi.org/10.1093/schbul/sbj021.

60. Warman DM, Lysaker PH, Martin JM, Davis L, Haudenschield SL. Jumping to conclusions and the continuum of delusional beliefs. Behav Res Ther. 2007; 45:1255-69. https://doi.org/10.1016/j.brat.2006.09.002.

61. Peters ER, Joseph SA, Garety PA. Measurement of delusional ideation in the normal population: introducing the PDI (Peters et al. delusions inventory). Schizophr Bull. 1999;25:553-76. https://doi.org/10.1093/oxfordjournals. schbul.a033401.

\section{Publisher's Note}

Springer Nature remains neutral with regard to jurisdictional claims in published maps and institutional affiliations.
Ready to submit your research? Choose BMC and benefit from:

- fast, convenient online submission

- thorough peer review by experienced researchers in your field

- rapid publication on acceptance

- support for research data, including large and complex data types

- gold Open Access which fosters wider collaboration and increased citations

- maximum visibility for your research: over $100 \mathrm{M}$ website views per year

At $\mathrm{BMC}$, research is always in progress.

Learn more biomedcentral.com/submissions 